\title{
O Programa de Iniciação à Docência e a Discussão sobre a Educação Especial
}

\section{The Teaching Initiation Program and the Discussion on Special Education}

\author{
Fernanda Welter Adams (adamswfernanda@gmail.com) \\ (Secretaria Municipal de Educação de Catalão) \\ Dulcéria Tartuci (dutartuci@gmail.com) \\ (Universidade Federal de Catalão - UDFCAT)
}

\begin{abstract}
Resumo: A história da pessoa com deficiência passou da segregação à inclusão, e, nesse contexto, o acesso e a permanência no ensino regular se tornaram direitos garantidos legalmente. Mas, observa-se que esses direitos somente serão facilitados se o professor possuir formação na área e o entendimento a respeito da importância da educação especial, e esta discussão deve ocorrer nos diversos espaços e momentos formativos, incluindo o Programa Institucional de Bolsas de Iniciação à Docência (Pibid). Diante do exposto, pretende-se apresentar como o Pibid dos cursos de ciências da natureza (Ciências Biológicas, Física e Química) do Estado de Goiás vem discutido a temática da educação especial com os futuros professores. Trata-se de uma pesquisa qualitativa que teve como referencial teórico a psicologia histórico-cultural e como instrumentos de construção de dados: análise do Projeto Pedagógico dos Cursos (PPC), questionário e entrevistas com coordenadores e licenciandos. Os dados foram analisados a partir da Análise Textual Discursiva. Observou-se que grande parte dos pibidianos teve contato com o aluno público alvo da educação especial durante a realização das atividades do projeto, mas poucos o envolveram nas atividades desenvolvidas. Assim, evidencia-se a necessidade de que a educação especial seja acrescentada nos objetivos do Pibid como forma de garantia da permanência desse aluno na escola e de seu desenvolvimento.
\end{abstract}

Palavras-chave: Pibid; Formação Inicial; Educação Especial

\begin{abstract}
The history of people with disabilities went from segregation to inclusion, and, in this context, access and permanence in regular education have become legally guaranteed rights. However, it is observed that these rights will only be facilitated if the teacher has training in the area and the understanding about the importance of special education, and this discussion should take place in the various spaces and formative moments, including the Institutional Program of Initiation Scholarships to Teaching (Pibid). Given the above, it is intended to present how the Pibid of natural science courses (Biological Sciences, Physics and Chemistry) of the State of Goiás has been discussing the theme of special education with future teachers. It is a qualitative research that had historical-cultural psychology as its theoretical framework and as instruments for data construction: analysis of the Pedagogical Course Project (PPC), questionnaire and interviews with coordinators and undergraduate students. The data were analyzed using the Textual Discursive Analysis. It was observed that a large part
\end{abstract}

Recebido em: $30 / 10 / 2019$

Aceito em: 01/07/2020 
of the pibidians had contact with the target public of special education during the performance of the project activities, but few involved him in the activities developed. Thus, it is evident the need for special education to be added to the objectives of Pibid as a way of guaranteeing the permanence of this student in school and his development.

Key Works: Pibid; Initial formation; Special Education

\section{INTRODUÇÃO}

Observa-se que, historicamente, as pessoas com deficiência foram, por muito tempo, discriminadas, excluídas e segregadas dos ambientes sociais. No contexto educacional, acreditava-se que elas não possuíam as mesmas condições de aprendizado que as demais e o atendimento que lhes era destinado ocorria de modo segregativo (PAULA, GUIMARÃES e SILVA, 2017). Esse tipo de atendimento foi justificado pela crença de que a pessoa "diferente" seria mais bem cuidada e protegida se estivesse em um ambiente separado das outras (DECHICHI, 2001; MENDES, 2006). Porém, a partir da década de 1990, essa visão foi sendo contestada e as pessoas público alvo da educação especial conquistaram o direito de serem atendidas nas escolas regulares. A Política Nacional de Educação Especial na Perspectiva da Educação Inclusiva (BRASIL, 2008) considera como público alvo da educação especial o aluno com deficiência, transtornos globais do desenvolvimento e altas habilidades e/ou superdotação.

De acordo com os principais documentos legais relacionados aos direitos dos alunos público alvo da educação especial, tais como a Lei de Diretrizes e Bases da Educação Nacional de 1996 - LDBEN (BRASIL, 1996) e a Declaração de Salamanca (UNESCO, 1994), a educação especial é uma modalidade de educação escolar oferecida na rede regular de ensino, ou seja, as leis asseguram o acesso e a permanência dos alunos público alvo da educação especial em todos os níveis, etapas e modalidades de educação.

A legislação garante o acesso desses alunos à escola, mas a permanência deve ser favorecida pelo professor, que precisa considerar as potencialidades dos mesmos, de modo a promover o seu processo de aprendizagem. Adams (2018) acredita ser de fundamental importância assegurar a formação de professores para lidarem com as potencialidades desse alunado, e, embora haja diretrizes legais que apontem sugestões de como essa formação deve ser feita, é preciso ir além e garantir, de fato, uma formação de professores na perspectiva da educação especial. 
Ao discutirem o ensino de ciências para alunos com deficiência, Souza e Messeder (2020) problematizam especialmente o ensino de conceitos que são abstratos, como é o caso da Biologia, e que estabelecem relação potente com recursos visuais. Os autores apontam, ainda, que no processo de ensino da Física, da Química e da Biologia, em uma perspectiva da educação especial, há escassez de recursos. Nesta direção, defendem uma aprendizagem diferenciada e individualizada para atender a esses alunos.

Nesse sentido, Ferreira (2000) e Benite et al. (2009) afirmam que a comunidade acadêmica vem discutindo a melhor maneira de formar os professores para a diversidade. Assim, a mudança na perspectiva da educação e da configuração das salas de aula acarreta também mudanças no perfil do professor que atuará nesse ambiente. Portanto, faz-se necessária a formação de professores na perspectiva da educação especial, para isso, é preciso que todos os cursos de licenciatura incluam em seus currículos disciplinas específicas que discutam a temática. Com relação a isso, Freitas (2006, p. 176) afirma:

Hoje, um dos grandes desafios dos cursos que formam professores é a elaboração de um currículo que venha desenvolver nos acadêmicos [...] conhecimentos para que possam atuar em uma escola realmente inclusiva, acessível a todos, independentemente das diferenças que apresentarem, dando-lhes as mesmas possibilidades de realização humana e social.

Ainda é um desafio incorporar aos currículos de formação de professores a discussão sobre a educação especial. Em relação à acessibilidade das pessoas surdas, os cursos de ciências da natureza, assim como outros cursos de licenciatura, incorporaram em seus currículos a disciplina Língua Brasileira de Sinais (Libras), esta medida foi implementada a partir do Decreto ${ }^{\circ} 5.626$, de 22 de dezembro de 2005.

A inserção apenas da disciplina Libras não é suficiente para promover uma formação inicial que capacite os futuros professores para desenvolverem práticas educativas que assegurem a escolarização dos alunos com deficiência. Destarte, considera-se a necessidade desta temática ser discutida não somente no âmbito das disciplinas, mas em todos os espaços formativos dos cursos de licenciatura, inclusive em projetos de pesquisa, em ações de extensão, nos estágios e em outros programas de formação, como o Programa Institucional de Bolsas de Iniciação à Docência (Pibid).

O Pibid tem se instituído como um importante espaço de melhoria e ampliação da formação de professores, uma vez que propicia que a Universidade estabeleça parceria e 
aproximação com escolas de educação básica da rede pública de ensino, de modo que essas últimas também sejam partícipes na formação dos licenciandos. O programa prevê bolsa aos estudantes de graduação dos cursos de licenciatura e a professores da educação básica no intuito de inserir os graduandos no âmbito escolar, proporcionando a eles a vivência da realidade do processo de ensino e aprendizagem em seu futuro contexto de atuação.

Dentre os inúmeros objetivos do Pibid pode-se destacar: elevar a qualidade da formação inicial de professores nos cursos de licenciatura, promovendo a integração entre educação superior e educação básica; e contribuir para a articulação entre teoria e prática necessária à formação dos docentes, elevando a qualidade das ações acadêmicas nos cursos de licenciatura. (CAPES, 2020)

Considera-se a participação dos alunos de cursos de licenciatura no Pibid como uma experiência de grande valia para a formação inicial de professores. Com relação às vivências no espaço escolar, Nóvoa (2004, p. 5) ressalta que:

É evidente que a Universidade tem um papel importante a desempenhar na formação de professores. Por razões de prestígio, de sustentação científica, de produção cultural. Mas a bagagem essencial de um professor adquire-se na escola, através da experiência e da reflexão sobre a experiência. Esta reflexão não surge do nada, por uma espécie de geração espontânea. Tem regras e métodos próprios.

Pensando na discussão sobre a educação especial na formação inicial dos professores, entende-se que esse espaço proporciona a oportunidade para o aluno reconhecer a heterogeneidade da sala de aula e assim refletir sobre como possibilitar o processo de ensino e aprendizagem a todos. Dessa forma, pretende-se com esse trabalho apresentar como o Pibid dos cursos de ciências da natureza (Ciências Biológicas, Física e Química) do Estado de Goiás vem discutido a temática da educação especial com os futuros professores.

\section{METODOLOGIA}

Este trabalho vincula-se à pesquisa de mestrado intitulada "Docência, Formação de professores e Educação Especial nos Cursos de Ciências da Natureza", que buscou investigar como ocorre a formação inicial na perspectiva da educação especial em cursos de Ciências Biológicas, Física e Química do estado de Goiás. Sendo o Pibid um 
espaço de formação, analisou-se de que modo este tema se apresenta em suas ações. $\mathrm{O}$ presente artigo expõe os dados referentes a este programa.

A pesquisa teve caráter qualitativo e buscou refletir sobre os dados a partir das concepções da psicologia histórico-cultural. Para Vigotski, todo conhecimento é sempre construído na inter-relação entre as pessoas, então, “[...] produzir um conhecimento a partir de uma pesquisa é, pois, assumir a perspectiva da aprendizagem como processo social compartilhado e gerador de desenvolvimento" (FREITAS, 2002, p. 25). A pesquisa representa um processo de construção de conhecimento, portanto, deve perpassar pelos campos histórico, cultural e social para promover a compreensão da essência do objeto de estudo e aproximar o pensamento desse objeto.

Com relação à pesquisa qualitativa, Martins (2004) afirma que essa é importante porque permite coletar evidências a respeito do tema abordado de maneira criadora e intuitiva, visto que há uma proximidade entre pesquisador e pesquisado, possibilitando a compreensão de crenças, tradições, em um máximo entrelaçar com o objeto em estudo. Segundo Zago (2003), uma pesquisa qualitativa deve permitir a compreensão da realidade homogênea do ambiente de estudo. Condição que se articula à percepção apontada anteriormente sobre pesquisador e participante da pesquisa.

Destaca-se que o presente estudo foi desenvolvido em um câmpus de cada Instituição de Ensino Superior Pública do Estado de Goiás, sendo elas: a Universidade Federal de Goiás, a Universidade Estadual de Goiás, o Instituto Federal Goiano e o Instituto Federal de Goiás. Isto posto, participaram da pesquisa nove cursos de ciências da natureza. Os dados que dão origem ao presente trabalhos são oriundos da aplicação de questionários e entrevistas semiestruturadas com licenciandos dos cursos investigados.

Com relação ao questionário, esse foi aplicado a todos os licenciandos dos dois últimos anos da graduação, totalizando 133 participantes, de forma presencial para evitar algumas de suas desvantagens como: a percentagem pequena de questionários que volta, o grande número de perguntas sem resposta, a dificuldade de compreensão das questões e a devolução tardia, que prejudica o calendário ou a utilização dos dados. O questionário possuía 23 questões que, em sua maioria, eram fechadas. Segundo Marconi e Lakatos (1999, p. 187), as perguntas fechadas são aquelas em que o informante escolhe sua resposta entre duas opções: sim e não. Optou-se por este tipo de 
questão, pois o número de participantes foi alto e as questões fechadas facilitariam o trabalhado de tabulação.

As questões do questionário que foram analisadas para a elaboração deste artigo foram: Durante a sua formação você participou de algum programa de incentivo à docência? Em caso afirmativo, qual (is)? e Dentro desse projeto ocorreu a discussão sobre a educação dos alunos público alvo da educação especial? Em caso afirmativo, como foi essa discussão? Faz-se necessário destacar que a análise dos dados não se pautou nas questões feitas aos licenciandos, mas sim em suas respostas.

O tempo médio gasto pelos licenciandos para responderem ao questionário foi de 25 minutos. Este foi aplicado aos licenciandos nas salas de aulas, durante as disciplinas de Estágio, Instrumentação Para o Ensino, Química Ambiental e Microbiologia, com o consentimento tanto do(a) coordenador(a) do curso quanto do(a) professor(a) da disciplina. Ressalta-se que a pesquisadora esteve presente durante a aplicação do questionário.

A entrevista também foi utilizada para construção de dados, fez-se uso desta por acreditar que a fala dos participantes que vivenciaram a atual formação inicial de professores seria de extrema importância para se conhecer como a educação especial tem sido discutida. Para tanto, entrevistou-se dois licenciandos do $8^{\circ}$ período dos cursos de ciências da natureza participantes. Como critério de escolha dos licenciandos que participariam da entrevista inicialmente determinou-se que um deles seria escolhido por meio de sorteio e, o outro, por indicação dos colegas. Mas, no primeiro momento de seleção dos entrevistados, a pesquisadora se deparou com uma turma que indicou dois licenciandos para participarem; desta forma, o critério de seleção foi alterado e os dois entrevistados foram indicados pela turma. Assim, entrevistou-se 19 licenciandos, sendo que em um dos cursos de Química um licenciando que não havia sido indicado demostrou interesse em participar, afirmando que gostaria de conhecer mais sobre a temática da pesquisa.

A entrevista foi de cunho semiestruturada, para Manzini (2006), este tipo de entrevista parte de um assunto sobre o qual é confeccionado um roteiro com perguntas principais abertas, sendo que pode existir flexibilização da sequência das perguntas ao entrevistado ou pode-se complementar a entrevista com outras questões inerentes às circunstâncias, de forma a se entender melhor a temática discutida. Dessa forma, as questões que nortearam as entrevistas referentes à participação dos licenciandos no 
Pibid foram: "Durante sua graduação você participou de um projeto de pesquisa, ou de ações de extensão, ou do Pibid? Como foi essa participação?"; "Você teve contato com alunos público alvo da educação especial? Descreva este contato."; e "Qual foi sua primeira visão do aluno PAEE? O aluno participou das aulas ou atividades desenvolvidas? Qual a deficiência? Como você vê os resultados desse aluno?”. Destacase que foi realizado um total de $5 \mathrm{~h} 17 \mathrm{~min} 54 \mathrm{~s}$ de entrevista com os licenciandos.

Para garantir o anonimato dos participantes foram criados códigos para a sua identificação. Dessa maneira, adotou-se os seguintes critérios: a letra L para os licenciandos participantes da entrevista, seguida dos números "1", "2". Para determinar a sequência, optou-se por utilizar a ordem alfabética dos cursos de ciências da natureza (Ciências Biológicas, Física e Química) e a ordem em que as entrevistas foram realizadas com os participantes, ficando os códigos de L1 a L19. Ao longo do trabalho também são apresentados excertos advindos das respostas aos questionários, pois os mesmos possuíam questões abertas, e, para diferenciá-los dos excertos das entrevistas, optou-se pela letra Q, assim, quando o excerto foi retirado do questionário foram usados os códigos de Q1 a Q133.

Após a coleta de dados realizou-se a tabulação e a análise dos mesmos, esses foram organizados em categorias com base na Análise textual Discursiva (ATD) (MORAES e GALIAZZI, 2007). Com relação à ATD, Moraes (2003) destaca que ela pode ser compreendida como um processo de construção e compreensão dos dados, com base em uma sequência recursiva de três componentes: a desconstrução do corpus, a unitarização, o estabelecimento de relações entre os elementos unitários, a categorização, e a captação do novo emergente em que nova compreensão é comunicada e validada.

Dessa forma, os dados da pesquisa - os discursos dos participantes - foram lidos de forma cuidadosa e organizados em unidades de análises. Os dados foram interpretados e isolados em ideias de sentidos sobre a temática, em seguida, realizou-se o processo de categorização, em que os dados foram agrupados por meio de sua similaridade, e, para finalizar, elaborou-se os metatextos, criando-se argumentos a partir da interpretação dos dados e do referencial teórico.

Esse processo permitiu a elaboração de diversas categorias, neste trabalho foram abordadas as categorias referentes à discussão sobre a educação especial no Pibid. As categorias aqui apresentadas são: “A participação dos Licenciandos no Pibid” e "“A 
Gente Levou Lupas e Diferentes Minerais com Características Físicas Diferentes para Mostrar que eles Têm Arranjos e Composições Diferentes': O Programa De Iniciação à Docência e a Educação Especial". O título da segunda categoria é a fala de um dos sujeitos que dá significado à percepção dos futuros professores frente aos desafios do ensino de ciências da natureza aos alunos PAEE, o que demonstra a relevância dessa categoria, uma vez que garantir o aprendizado desses alunos já se mostra como um desafio, sendo assim, essa temática precisa ser discutida na formação de professores nos mais variados espaços, incluindo o Pibid.

Destaca-se que essa categoria permitiu interligar os dados coletados tanto por meio dos questionários, que são apresentados em forma de gráficos, quanto das entrevistas, que são expostas por meio de excertos; esse cruzamento deu mais significado às discussões realizadas na categoria a ser apresentada.

\section{A PARTICIPAÇÃO DOS LICENCIANDOS NO PIBID}

O Pibid tem como meta elevar a qualidade das ações acadêmicas voltadas à formação inicial de professores nos cursos de licenciatura das Instituições de Educação Superior (IES) por meio da inserção dos licenciandos no cotidiano de escolas da rede pública de educação (GIMENEZ e CHAVES, 2019). Com relação aos objetivos do Pibid, Adams et al. (2019, p. 25) discutem que:

Para essa aproximação entre os conhecimentos acadêmicos e a dimensão prática da formação docente as Universidades contam hoje com políticas públicas e programas como o Pibid (Programa Institucional de Bolsa de Iniciação à Docência), que busca estabelecer uma relação entre Universidade e escola no intuito de aprimorar o modelo de formação docente, assim como um dos seus principais objetivos, que é a melhoria na formação inicial de professores, visando elevar a qualidade das ações acadêmicas voltadas para uma formação inicial de qualidade. Para isto, busca-se a inserção dos licenciandos em seu futuro local de atuação (as escolas) a fim de que conheçam a complexa realidade escolar, bem como a aproximação entre ensino superior e ensino básico, estreitando as relações entre teoria e prática.

Por meio dos objetivos pode-se observar que o Pibid não aborda, em suas diretrizes, a educação especial. Mas, com a garantia legal de acesso e permanência dos alunos público alvo da educação especial no ensino regular, verifica-se que o número de matrículas desses aumentou. Dados do Censo Escolar de 2018, divulgados pelo Instituto Nacional de Estudos e Pesquisas Educacionais Anísio Teixeira (Inep), revelam um 
aumento de 33,2\% no número de matrículas dos estudantes público alvo da educação especial no período entre 2014 e 2018. Assim, considera-se que em algum momento de sua participação no programa o licenciado terá contato com esse aluno.

Sendo o Pibid um espaço que contribui com a formação de professores, observase a necessidade deste abarcar em suas atividades essa discussão. Assim, os licenciandos participantes desta pesquisa foram inqueridos no questionário se participaram em sua formação de projetos de pesquisa, ações de extensão, ou de outros programas de formação, como Pibid, os resultados são apresentados no Gráfico 1.

Gráfico 1 - Participação dos licenciandos em projetos de pesquisa, ações de extensão e Pibid.

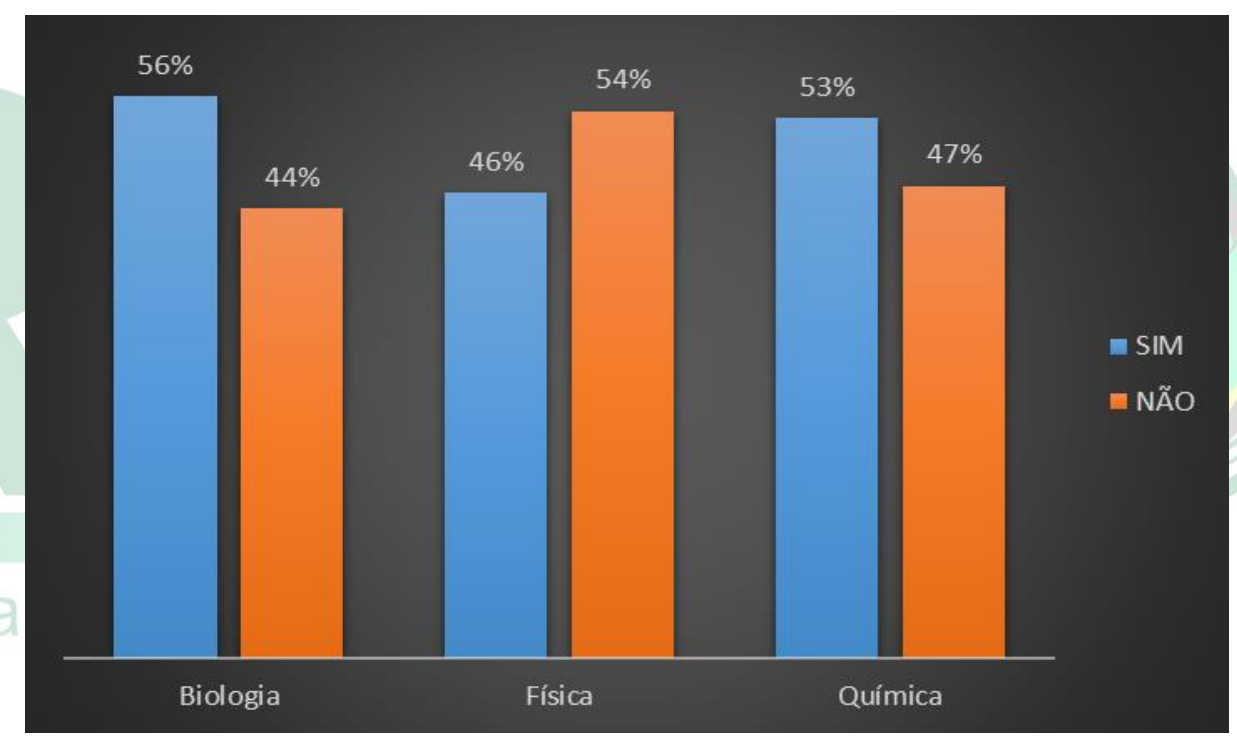

Fonte: Produção própria a partir de dados do questionário (2018)

Pela análise do gráfico constatou-se que nos cursos de Ciências Biológicas 56\% dos licenciandos participaram de projetos de pesquisa, ações de extensão, ou de outros programas de formação, como o Pibid, nos cursos de Química, 53\%, e, nos cursos de Física, $46 \%$. Os números indicam que mais de $50 \%$ dos alunos dos cursos de ciências da natureza investigados participaram de algum projeto ou programa de formação durante a graduação, destes, 30\% participaram do Pibid e os demais de ações de extensão ou de algum projeto de pesquisa.

No excerto 1, pode-se observar a fala de L1, que cita sua participação em um projeto de pesquisa: 
Excerto 1 - Eu trabalhei com um projeto a partir da disciplina de educação ambiental que a gente teve. Não foi com alunos especiais, mas a gente quer estender esse projeto para estes alunos. O projeto era para conscientização da importância do cerrado, então trabalhamos com a questão do sentir e do toque, a gente fez uma trilha interpretativa onde os alunos ficavam de olhos vendados para sentirem os componentes presentes na trilha. A gente pensou em estender esse trabalho para alunos especiais, mas ainda não temos muita bagagem para trabalhar com estes alunos. L1/Licenciando da Ciências Biológicas.

O licenciando cita um projeto de educação ambiental em que trabalhou a importância do cerrado por meio do toque, nessa atividade os alunos realizaram uma trilha interpretativa para sentirem os componentes da mesma, pela fala do licenciando acredita-se que a atividade foi realizada apenas com alunos sem deficiência, uma vez que seus olhos foram vendados. Mas, pode-se verificar pelos seus dizeres a sua vontade de desenvolver o mesmo projeto com os alunos com deficiência visual, mas, constata-se que ele dá indícios de não se sentir seguro para realizar tal prática ao afirmar "não ter bagagem para trabalhar com estes alunos".

Esse dizer é muito comum entre licenciandos e professores atuantes que nunca vivenciaram o trabalho com alunos público alvo da educação especial, haja vista que os mesmos apresentam o medo do novo, de experienciar, de trabalhar com esse público, que é desconhecido para eles. Costa (2007) corrobora com o exposto ao realizar uma pesquisa com dez professores sobre os sentimentos desses frente a práticas inclusivas. A autora percebe que os docentes citam o despreparo e a insegurança como sentimentos que dificultam a inclusão, resultado da falta de recursos, das dificuldades frente à metodologia de ensino e ainda da falta de formação. Adams (2018; 2020) também explica que quando o assunto é educação especial o que se observa é a formação de profissionais despreparados e aflitos, com receio de chegarem a seu ambiente de trabalho e não terem noção de como abordar os conhecimentos científicos de forma a contribuir para o processo de ensino e aprendizagem desses alunos.

Ainda de acordo com Giordan e Hobold (2015, p. 57), "apesar da obrigatoriedade da inclusão de alunos com deficiência, esta, por si só, não garante o trabalho docente para a inclusão de toda a diversidade." Segundo as autoras, é indispensável a formação de professores em relação à educação especial, pois os mesmos, quando iniciantes na carreira docente, possuem um sentimento de insegurança por não terem a instrução necessária para trabalharem com esses alunos, além disso, muitos docentes afirmam que 
se sentem incapazes e despreparados para incluírem esses discentes (GIORDON e HOBOLD, 2015).

Dessa forma, destaca-se que essa insegurança será suprida por meio de formação inicial e continuada frente à temática da educação especial. Quanto à formação inicial, discutir-se-á, a seguir, se essa se faz presente no Pibid de cursos de ciências da natureza no Estado de Goiás, mesmo este não sendo um de seus objetivos.

\section{4. "A GENTE LEVOU LUPAS E DIFERENTES MINERAIS, COM} CARACTERÍSTICAS FÍSICAS DIFERENTES PARA MOSTRAR QUE ELES TÊM ARRANJOS E COMPOSIÇÕES DIFERENTES": O PROGRAMA DE INICIAÇÃO À DOCÊNCIA E A EDUCAÇÃO ESPECIAL

A discussão sobre a educação especial deve ser inserida nos cursos de formação inicial em ciências da natureza, abordando, principalmente, como ocorre o processo de desenvolvimento desse aluno para facilitar que o professor o inclua nas atividades. Portanto, promover espaços de reflexão sobre essa temática na formação de professores é fundamental para que esses se sintam preparados e vejam os alunos público alvo da educação especial como sujeitos capazes de aprender.

Com base nos escritos de Vigotski e Luria (1996), todos podem aprender e, por isso, desenvolver-se. Todos podem encontrar, em caso de deficiência, meios de desenvolver o talento cultural, isto é, a capacidade de empregar de modo mais eficaz possível as funções que estão íntegras. Quando falta o talento biológico, as mediações culturais contribuem para a construção de um novo edifício: a formação do homem cultural, com todas as compensações possíveis. Com relação a isso, Rego (1995, p. 107) afirma que:

\footnotetext{
O bom ensino é aquele que se adianta ao desenvolvimento, ou seja, que se dirige às funções psicológicas que estão em vias de se completarem. Essa dimensão prospectiva do desenvolvimento psicológico é de grande importância para a educação, pois permite a compreensão de processos de desenvolvimento que, embora presentes no indivíduo, necessitam da intervenção, da colaboração de parceiros mais experientes da cultura para se consolidarem e, como consequência, ajuda a definir o campo e as possibilidades da atuação pedagógica
}

Consoante com Vigotski (1997, p.128), a criança com deficiência é, antes de tudo, uma criança, e somente depois é uma criança deficiente. Logo, "não se deve perceber na 
criança com deficiência apenas o defeito, os gramas de doença, não se notando os quilogramas de saúde que a criança possui." Pensando no Pibid como um espaço de formação com potencial para promover essa discussão, uma vez que permite o contato dos licenciandos com a realidade escolar, ou seja, com os alunos, perguntou-se aos licenciandos se ocorre no programa a discussão sobre a educação especial, os resultados são apresentados no Gráfico 2.

Gráfico 2 - Discussão da Educação Especial no Pibid.

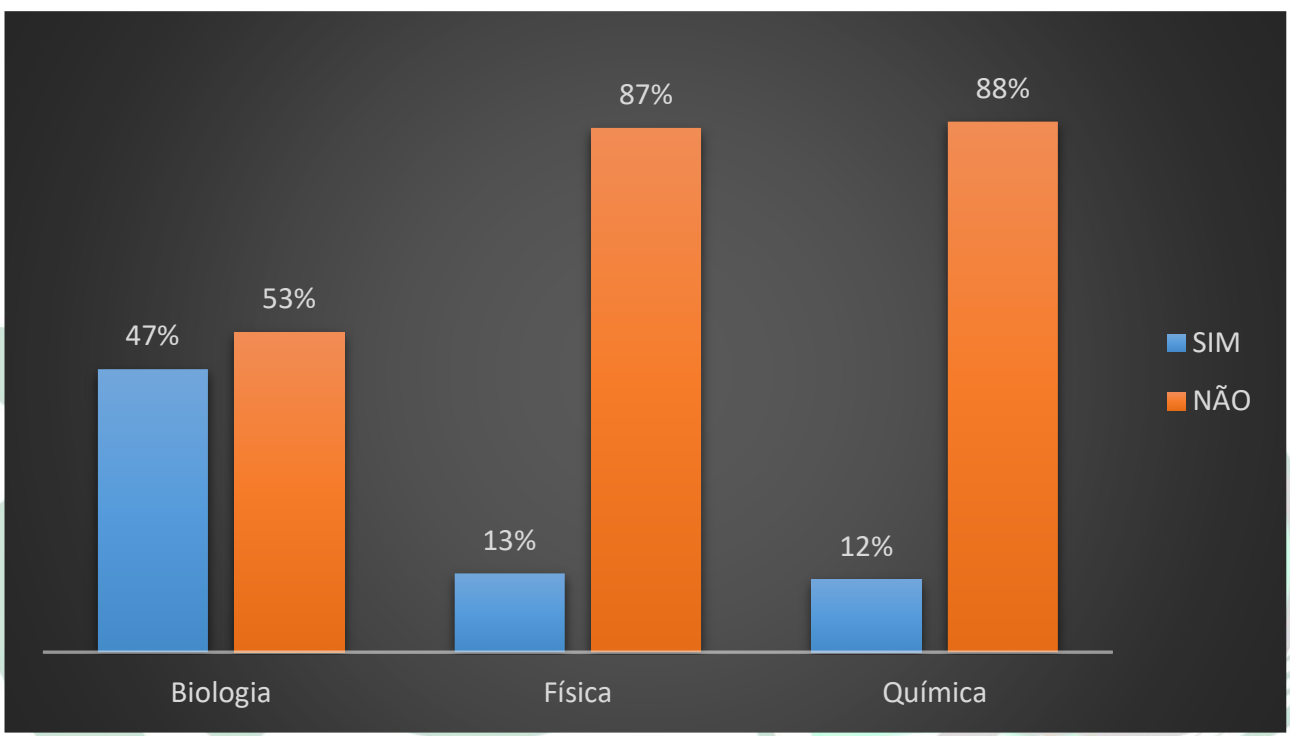

Fonte: Produção própria a partir de dados do questionário (2018)

Por meio dos dados apresentados no Gráfico 2, que foram coletados através do questionário, observa-se que a maioria dos licenciandos que participaram do Pibid não vivenciou a discussão sobre a educação especial no programa, acredita-se que isso se deve ao fato de a temática não constar nas diretrizes do mesmo. Nesse contexto, problematiza-se a falta da discussão sobre essa temática, uma vez que a presença dos alunos público alvo da educação especial na escola é uma realidade.

Com relação a essa realidade, Bezerra (2012) destaca que, nos últimos anos, a inclusão escolar de alunos com deficiência tem sido cotidianamente vivenciada nas escolas comuns de todo o país, ainda que se possam lançar muitas críticas ao modo como a perspectiva da educação inclusiva foi sendo concebida e operacionalizada no Brasil. Vale ressaltar que a ampliação do atendimento aos educandos com deficiência na rede pública de ensino e nas salas de aula comuns concretizou-se, sobretudo, com o lançamento em 2008, pelo Ministério da Educação (MEC), da Política Nacional de 
Educação Especial na Perspectiva da Educação Inclusiva (Brasil, 2008). Essa política, pelo menos em tese, aboliu a matrícula de alunos com deficiência em escolas ou classes especiais de forma substitutiva à escola comum, embora na prática isso nem sempre tenha acontecido (BEZERRA, 2017).

Durante a entrevista, realizada com 19 licenciandos, foi possível aprofundar a questão sobre a discussão da temática no Pibid. Dos entrevistados, 16 licenciandos afirmaram terem participado do programa, sendo que oito tiveram contato com alunos público alvo da educação especial e quatro realizaram alguma intervenção com os alunos.

Os licenciandos que tiveram contato com alunos público alvo da educação especial e não desenvolveram atividades com os mesmos relataram não terem sido incentivados ou não tiveram interesse em incluir estes alunos nas atividades desenvolvidas:

Excerto 2 - Tem, um aluno que é surdo, ele tem a professora que faz o acompanhamento (professora de apoio), mas assim os projetos que a gente desenvolve são voltados para os alunos de maneira geral, não tem um projeto específico para alunos com necessidades especiais. L2/Licenciandos das Ciências Biológicas.

Excerto 3- Com certeza (E o programa ou o professor orientador te incentivaram incluir este aluno nas aulas, a desenvolver alguma atividade para ele?) Nada a gente só vai na escola e aplica alguma atividade, na maioria das vezes deixa este aluno lado, já atendemos muitos alunos na escola, se dá para auxiliar a gente auxilia, mas é difícil de acontece. O professor orientador não falou nada para auxiliar o aluno e nem mesmo os professores da sala de aula, eles pedem para deixar mais para o lado vamos dizer assim é muito chato. L5/ Licenciandos das Ciências Biológicas.

Por meio da análise dos excertos, pode-se observar que os licenciandos não foram instruídos pelos professores orientadores a incluírem os alunos público alvo da educação especial nas atividades desenvolvidas e mais alarmante ainda é a afirmação do excerto três de que até os professores supervisores do projeto também não incentivaram levar a presença do aluno na sala de aula em consideração; esperava-se que este, por ter a presença do aluno cotidianamente em sala de aula, incentivasse o licenciando a incluir o aluno de forma a promover o processo de ensino e aprendizagem do mesmo.

Evidencia-se mais uma vez que o licenciando afirma ter o contato com o aluno público alvo da educação especial, mas este espaço de formação não é aproveitado pelo professor orientador e pelo professor supervisor. Este deveria ser um momento em que o licenciando teria a oportunidade de vivenciar a prática com o aluno, tendo a chance de conhecer como se dá o processo de ensino e aprendizagem, pois a formação inicial é o 
momento de desenvolvimento profissional, e sabe-se que o futuro professor irá se deparar com alunos com deficiência, transtornos globais do desenvolvimento, altas habilidade e/ou superdotação em sala de aula, então, o mesmo deve ser preparado para isso. Wartha e Gramacho (2010) corroboram com essa ideia afirmando que os futuros professores só poderão analisar criticamente o ensino e construir propostas inovadoras se vivenciarem estas propostas em seus cursos de formação. Portanto, é urgente que se mude a concepção de formação de professores.

Apesar de não se conhecer o processo de formação inicial e continuada do professor orientador e do supervisor a que os licenciandos se referem, observa-se que este fato pode ter ocorrido devido à falta de formação destes frente à temática da educação especial. Segundo Vilela-Ribeiro (2011), a formação de docentes universitários para a educação especial é tema ainda incipiente em pesquisas e muitos professores formadores não vivenciaram a temática. Portanto, acredita-se que o professor formador promoverá as discussões sobre a temática a partir do momento em que tiver conhecimento sobre a mesma, sendo então necessário que vivencie uma formação continuada sobre ela.

Corroborando com essa discussão, Vilela-Ribeiro (2011) afirma que para haver uma implantação real de práticas inclusivas nas Universidades é preciso repensar a formação continuada de seus professores, de modo que eles conheçam o assunto e saibam se posicionar crítica e reflexivamente no ensino. E, para Alves e Araújo (2017), a formação continuada dos professores da Educação Especial é muito relevante, pois capacita e atualiza esses profissionais para o melhor atendimento educacional desse público discente. Assim, as escolas devem se atentar para as necessidades e individualidades dos seus alunos, respeitando a aprendizagem de cada um.

Em contrapartida ao que foi dito por L2 e L5, no excerto a seguir tem-se o relato de L9, que buscou em seu professor orientador o auxílio para a realização de uma atividade com os alunos público alvo da educação especial:

Excerto 4 - Nos que propomos de elaborar uma atividade para ajudar a aluna, porque no Pibid a gente propõe muito o que vamos fazer e desenvolver, partiu da gente mesmo. ((Mas vocês tiveram auxílio do professor orientador ou buscaram internet, literatura, etc.?)) [...] Ele contribuiu muito, mas a maior parte foi a gente procurando por fora mesmo, mas ele é muito disposto a ajudar. ((Vocês estudaram as especificidades da deficiência teoricamente, leram algum trabalho?)) [...] O professor Lucas ele disponibilizou um livro que ele tem sobre práticas para com alunos cegos, depois disso a gente teve uma ideia de como é, porque o livro ele relata exatamente como foi a aula, lendo a gente teve uma ideia de como trabalhar com um aluno cego que é um pouco diferente. L9/Licenciando da Física

Recebido em: 30/10/2019

Aceito em: 01/07/2020 
Verifica-se que o licenciando teve a iniciativa, mas teve também o auxílio do professor orientador do Pibid, que passou para ele, primeiramente, um material para estudo, para que conhecesse mais sobre a deficiência visual. Considera-se esta uma prática formativa, pois o professor somente consegue elaborar uma prática efetiva de aprendizagem para alunos público alvo da educação especial se este conhecer a especificidade da deficiência com a qual irá desenvolvê-la.

Destaca-se o relato do licenciando como momento de troca de experiência entre graduando e professor formador, de discussão sobre o tema e de incentivo para a realização do trabalho com o aluno público alvo da educação especial. No mesmo sentido, Mizukami (2004) fala da necessidade do trabalho colaborativo, das socializações e das trocas de experiências ainda na formação inicial. A autora entende que "[...] é preciso, pois, começar a vivê-las nos cursos de formação inicial; de modo a serem instalados, nesse momento formativo, atitudes investigativas e comprometimento com a autoformação" (MIZUKAMI, 2004, p. 27). Vê-se, nesse momento, como a orientação e o incentivo são importantes no processo de formação dos futuros professores, e, mesmo com a iniciativa sendo do licenciando, o professor formador estava disposto a contribuir e emprestou material para a pesquisa, enfim, viu a importância dessa experiência para a formação desse professor. Acredita-se que este será um professor que vê os alunos público alvo da educação especial na sala de aula e se preocupará com o processo de ensino e aprendizagem deles. Além disso, ressalte-se que as vivências da formação inicial podem influenciar a construção de um profissional qualificado.

Outros licenciandos participantes do Pibid buscaram incluir o aluno público alvo da educação especial nas atividades desenvolvidas por eles em sala de aula:

Excerto 5- Tive contato, com o aluno no EJA, no terceiro ano do Ensino Médio [...] ele, deficiência auditiva professora de apoio tinha que conversar com ele em Libras [...] Não, desenvolvi atividade com o aluno específico não, tentamos incluir ele juntamente com toda a sala, como era uma sala de EJA, os alunos eram bem diversificados, então tentamos fazer algumas atividades práticas, para tentar alcançar todo mundo [...] montamos uma aula de minerais, se não me engano levamos lupas e diferentes minerais, com características físicas diferentes para mostrar que eles tem arranjos e composições diferente; eles ficaram super empolgados vendo ali as configurações e conseguindo diferenciar os minerais. L6/Licenciando de Ciências Biológicas.

Excerto 6 - Tivemos contato com uma aluna deficiente visual. Percebemos que na física onde precisa desenhar para o pessoal entender, como ela não tinha esse recurso ela ficava muito perdida e nos contava isso, então pensamos em desenvolver alguns materiais para auxiliar nessa visualização [...] tentamos trabalhar alguns conceitos de gráfico, de vetor conceitos mais gerais que eram a dificuldade que ela fala ter, tentamos facilitar a visualização [...], elaboramos uns

Recebido em: 30/10/2019

Aceito em: 01/07/2020 
pontinhos assim ((mostra como eram os pontinhos na mesa se referindo ao uso do braile)) para montar os eixos cartesianos e a partir da ligação destes pontinhos ela formava uma função que dava origem a um gráfico. L9/Licenciando da Física

Excerto 7 - Nós estamos orientando na feira de ciências, que vai acontecer dia primeiro de novembro e tem uma aluna especial, ela tem uma deficiência visual e a gente está pensando em alguma coisa para que ela possa participar da feira, conversando com a coordenadora da escola, ela disse para fazer uma coisa bem simples porque senão ela não ia conseguir participar ou explicar o experimento. Ela (a coordenadora) disse para pegar um modelo da molécula de água, fazer a sua estrutura, com bolinhas de isopor e pedir para ela explicar que o hidrogênio seriam as bolinhas menores e o oxigênio a bolinha maior só isso [...]. L16/Licencianda em Química.

Excerto 8- Desenvolvemos algumas atividades com uma aluna especial. ((O conteúdo trabalhado com os demais alunos e com ela foi o mesmo?)) Não. ((Por que não trabalharam o mesmo conteúdo?)) Porque a sala já tinha passado desse conteúdo [...] era o conteúdo de vetor, grandezas escaleres vetoriais, é um conteúdo fundamental para todos anos da física e ela não conseguir visualizar muito bem, ela mesmo havia falado isso com a gente, por isso escolhemos esse e trabalhos com ela fora da sala. ((Por que a escolha de tirar ela de sala de aula e não trabalhar com ela e com os demais alunos?)) Porque aí a gente estaria congelando a aula, a gente teria que voltar com todo mundo, assim acho que o professor não ia gostar muito disso [...] Acredito que daria para trabalhar com todos os alunos. L5/Licenciando da Física

Por meio dos dizeres dos licenciandos pode-se observar que estes tiveram contato com alunos com deficiência visual e auditiva. L6 cita que teve contato com um aluno com deficiência auditiva quando desenvolveu atividades em uma escola de educação de jovens e adultos (EJA) que, segundo ele, dá muita importância à diversidade e à inclusão, não só do aluno público alvo da educação especial, mas de todos os alunos. As escolas devem ser comunidades que atendem a todos, já que as diferenças humanas são naturais, diga-se, existem, havendo, porém, a necessidade de adaptar a aprendizagem a cada criança (TIERNEY, 1993). Portanto, todas as crianças têm direito à educação e deve-se dar a elas a oportunidade de alcançar e manter um nível aceitável de conhecimentos. (UNESCO, 1994)

Destaca-se o trecho "Não, desenvolvi atividade com o aluno específico não, tentamos incluir ele juntamente com toda a sala", que demostra que o licenciando atuou de forma inclusiva, pois não desenvolveu uma atividade específica para o aluno com deficiência, mas buscou a interação deste com o restante da turma, ou seja, o relato da atividade desenvolvida demostra indícios de que o licenciando tem uma visão de que o aluno com deficiência é capaz de se desenvolver e, portanto, deve ser incluído nas atividades de sala de aula. Nesse sentido, Vygotsky $(2011 ; 2012)$, ao abordar o desenvolvimento da criança com deficiência, afirma que esse processo se dá de forma igualitária para todas as crianças, independentemente da deficiência que a mesma possua.

Recebido em: $30 / 10 / 2019$

Aceito em: 01/07/2020 
Uma educação inclusiva não deve significar somente a inserção da criança no ambiente escolar ou a efetivação de sua matrícula, mas a adaptação da escola no atendimento a suas especificidades de vida e de aprendizagem. Para tanto, faz-se necessário que as escolas e seus professores se atentem para as singularidades dos sujeitos e se responsabilizem pela aprendizagem de todos os alunos (CRISTOFOLI e NUNES, 2019).

Nos dizeres de L9, L16 e L5 também é possível observar uma preocupação dos licenciandos em incluir os alunos público alvo da educação especial nas aulas e atividades desenvolvidas. L9 elaborou uma forma de trabalhar gráficos e vetores com uma aluna com deficiência visual por meio do braile, isso a partir de uma conversa com a própria aluna que relatou a dificuldade frente ao conteúdo discutido, assim, o licenciando buscou uma forma de compensar a deficiência da aluna e promover o aprendizado da mesma. Com relação à compensação, Vigotski (1997, p. 47) afirma que:

Se algum órgão, devido à deficiência morfológica ou funcional, não cumpre seu trabalho, então o sistema nervoso central e o aparato psíquico assumem a tarefa de compensar o funcionamento insuficiente do órgão, criando sobre este ou sobre a função, uma superestrutura psíquica que tem a tendência de assegurar o organismo no ponto débil ameaçado.

A compensação refere-se ao processo substitutivo que garante o desenvolvimento, ou seja, quando uma ou mais vias de apreensão do mundo e de expressão não estão íntegras ou não podem ser formadas, o indivíduo pode eleger outras que estejam íntegras. Isso lhe permite estar no mundo e com ele se relacionar. Acontece, no entanto, que em alguns casos o indivíduo não apenas compensa o que lhe falta, mas vai além. Ele pode compensar, isto é, apresentar um grau de adaptação na área em que tinha limites biológicos a um nível acima da média esperada para a sociedade na qual está inserido e com a qual se humaniza (COELHO, BARROCO e SIERRA, 2011).

Os autores ainda evidenciam que estamos diante de uma teoria que não valoriza e não se conforma com o sofrimento e com os limites biológicos, mas que busca a superação destes, impulsionando para o estabelecimento de novos posicionamentos a respeito de velhas questões, como a de que deficiência é fator de impedimento ao desenvolvimento. Essa concepção de que a deficiência não é somente uma debilidade, mas também potencialidade resulta em uma importante referência em favor das 
possibilidades para o pedagogo, o psicólogo e outros profissionais em seus trabalhos junto à educação (COELHO; BARROCO e SIERRA, 2011).

Nos dizeres de L16 observa-se que o licenciando tentou incluir uma aluna público alvo da educação especial em uma atividade que estava sendo desenvolvida na escola, a feira de ciências, e, para isso, procurou o auxílio da coordenadora da escola. Mas, através da fala do licenciando, verifica-se que a busca foi frustrada, pois ele recebeu a orientação de realizar uma "coisa bem simples, porque senão ela (a aluna público alvo da educação especial) não ia conseguir participar ou explicar o experimento".

Evidencia-se, por meio da direção dada pela coordenadora da escola, a crença de que a aluna não possui a capacidade de fazer uso do conhecimento científico para explicar um projeto/experimento na feira de ciências e, ainda, de que este deveria ser elaborado pelo licenciando. Observa-se, nos dizeres da coordenadora, a cultura da crença na incapacidade de aprender do aluno público alvo da educação especial, cultura essa que somente poderá ser superada por meio de uma formação inicial e continuada que discuta as potencialidades dos alunos. De acordo com Góes (2002), o educador precisa privilegiar as potencialidades e os talentos do aluno, recusando a suposição de limites para o que pode ser alcançado. Mesmo nas limitações intelectuais muito graves é possível manter uma concepção prospectiva e a diretriz de mobilização de forças compensatórias, partindo de atuações em que o outro faz pela criança o que ela não pode fazer (GÓES, 2002, p. 103).

Constata-se que uma solução para a situação relatada por L16 seria inserir a aluna público alvo da educação em um grupo em que ela pudesse trabalhar em colaboração com os colegas e assim se desenvolver a partir de suas potencialidades. Portanto, entende-se que a escola não é inclusiva e que isso é transmitido aos futuros professores ao vivenciarem experiências de formação em seu espaço. Rego (1995, p. 110) explica que "[...] na perspectiva de Vygotsky, construir conhecimentos implica numa ação partilhada, já que é através dos outros que as relações entre sujeito e objeto de conhecimento são estabelecidas”. A autora ainda afirma que as interações vinculadas ao diálogo, à cooperação e à troca de informações são condições necessárias para a produção de conhecimentos.

No relato de L5 observou-se que o mesmo identificou uma dificuldade da aluna com deficiência visual frente ao conteúdo de vetores e buscou desenvolver uma atividade para contribuir com a aprendizagem dela.

Recebido em: $30 / 10 / 2019$

Aceito em: $01 / 07 / 2020$ 
Mas, para desenvolver a atividade com a aluna, o licenciando a tirou de sala de aula, uma prática com a qual este estudo não concorda, uma vez que a legislação garante o acesso e a permanência do aluno público alvo da educação especial na sala regular de ensino, tendo ele o direito ao Atendimento Educacional Especializado no contra turno de forma complementar ou suplementar (BRASIL, 2008), sendo assim, as práticas desenvolvidas com o aluno devem ocorrer em sala de aula, de preferência envolvendo toda a turma.

Quando questionado sobre o motivo de ter tirado a aluna de sala para desenvolver a atividade, o licenciando afirmou: "Porque aí a gente estaria congelando a aula, a gente teria que voltar com todo mundo, assim acho que o professor não ia gostar muito disso". Ao retirar a aluna de sala de aula ele vai contra as ideias de inclusão e apenas repete uma prática que é comum nas escolas ditas inclusivas. Destaca-se a visão do licenciando em relação à dificuldade da aluna e sua intenção de buscar uma forma de saná-la, mas salienta-se a necessidade de uma formação inicial de qualidade que prepare os futuros professores para que desenvolvam práticas adequadas de inclusão, levando em consideração as potencialidades do aluno e sua presença na sala regular.

Nesse sentido, Kierepka e Zanon (2019), a partir de Demo (2020), apontam a necessidade de que os processos pedagógicos se organizem de modo que os alunos possam ser protagonistas, evidenciando, assim, a demanda pela organização da sala de aula de modo a assegurar a participação de todos e que o professor assuma o papel de mediador e responsável pela construção autônoma do conhecimento do aluno.

Contribuindo com a fala dos autores, o Pibid tem se consolidado como uma iniciativa muito importante no que diz respeito à formação inicial dos acadêmicos das licenciaturas. Esse vem preencher lacunas existentes na maioria dos currículos dos cursos de licenciatura, especialmente em ciências da natureza. Estes programas aproximam o licenciando da realidade escolar, espaço que proporciona uma rica formação e contribui com a criação da identidade docente. Nele, os licenciandos lidam com situações reais e podem refletir sobre elas e assim se prepararem para o que irão enfrentar quando se formarem. Portanto, é um espaço privilegiado para reflexões, aquisição de conhecimentos e implicações práticas. Concomitantemente, permite a interação entre os licenciandos e os professores da escola, o que pode contribuir também com a formação inicial dos licenciados ou, ainda, com a formação continuada dos professores de ciências da natureza, aproximando formação inicial e continuada.

Recebido em: $30 / 10 / 2019$

Aceito em: 01/07/2020 
Pelo exposto, vê-se no Pibid, enquanto espaço de formação, as suas potencialidades para promover a discussão sobre a educação especial na formação inicial dos professores, uma vez que ele permite o contato direto com a sala de aula regular, sendo então necessário que essa temática seja incluída nas diretrizes do programa. Corroborando com essa afirmação, Q102 afirma sobre o Pibid enquanto espaço para a discussão da educação especial:

Excerto 9 - No Pibid pode-se trabalhar mais fortemente a inclusão pelo fato do discente ter contato direto com os alunos Q102/Licenciando da Química

Nesse enunciado, verifica-se que o licenciando concorda que o Pibid, por proporcionar o contato com o aluno, é um espaço para a discussão sobre a educação especial. Mas, o que se pode observar pelos dados da pesquisa é que ainda pouco se tem discutido sobre a educação especial no programa, e que apenas alguns licenciandos buscam desenvolver atividades que incluam os alunos público alvo da educação especial, e quando as realizam, muitas vezes por não receberem uma orientação correta sobre como deve ser o processo de inclusão, desenvolvem atividades de forma errônea ou, ainda, ao invés de incluírem o aluno, acabam excluindo o mesmo.

Mas essas tentativas devem ser valorizadas, e acredita-se que será por meio delas e da reflexão sobre elas que se poderá construir uma educação especial forte, pautada na valorização das potencialidades dos alunos público alvo da educação especial, e se poderá lutar pela garantia da discussão sobre a temática em programas como o Pibid.

\section{CONSIDERAÇÕES FINAIS}

Defende-se o Pibid como um rico espaço de formação inicial para os licenciandos por permitir que esses tenham o contato com a realidade escolar por meio do desenvolvimento de práticas pedagógicas e também da teoria. A partir desse contato do licenciando com a escola e da garantia legal do acesso e da permanência do aluno público alvo da educação especial na sala de aula regular, observa-se as possibilidades do Pibid em promover tal discussão e vivência aos futuros professores.

Dessa forma, buscou-se neste trabalho apresentar como o Pibid dos cursos de ciências da natureza (Ciências Biológicas, Física e Química) do Estado de Goiás vem discutido a temática da educação especial com os futuros professores. Por meio dos 
dados foi possível verificar que as discussões sobre a temática são incipientes, uma vez que a maioria dos licenciandos afirmou que não há a presença da temática no programa e apenas quatro desenvolveram atividades que buscaram incluir os alunos público alvo da educação especial, sendo que algumas das atividades desenvolvidas não estavam em consonância com a ideia de inclusão defendida por este estudo de que o aluno público alvo da educação especial é capaz de se desenvolver por meio de caminhos alternativos, que podem ser recursos e metodologias. Essas últimas devem ser elaboradas a partir das potencialidades dos alunos, bem como aplicadas tanto com os alunos público alvo da educação especial, quanto com os demais alunos.

A partir da pouca discussão frente à temática da educação especial no Pibid e da capacidade de contribuição do programa para a formação inicial e continuada de professores, evidencia-se a necessidade de que essa temática seja comtemplada nos objetivos do programa como forma de contribuir para a permanência e o desenvolvimento do aluno público alvo da educação especial na educação básica.

\section{REFERENCIAS}

ADAMS, F. W. Discussão da Educação Especial nas Disciplinas de Núcleo Pedagógicas nos Cursos de Ciências da Natureza. Anais... $3^{\circ}$ Encontro das Licenciaturas e Pesquisas em Educação (ELPED) e $4^{\circ}$ Encontro das Licenciaturas e Pibid do Sudeste Goiano, Rio Verde, v. 3, n. 1, 2018.

Docência, Formação de Professores e Educação Especial nos Cursos de Ciências da Natureza. 2018. 264f. Dissertação (Mestrado em Educação), Universidade Federal de Goiás, Catalão, 2018.

ADAMS, F. W. Abordagem Histórico-Cultural: um olhar para a formação de professores e a educação especial. 1. ed. Curitiba: Editora Appris, 2020.

ADAMS, F. W.; ALVES, S. D. B.; NUNES, S. M. T. Percepções de pibidianos após a elaboração de suas primeiras aulas: o programa tem cumprido seus objetivos? Revista Iluminart, São Paulo, no 17, dezembro, 2019.

ALVES, C. B.; ARAÚJO, M. I. Formação Continuada dos Profissionais da Educação Especial da Rede Municipal de Uberlândia: Seu Saber e Fazer. 2017. Disponível em: <http://www.eventos.ufu.br/sites/eventos.ufu.br/files/documentos/formacao_continuada _dos_profissionais_da_educacao_especial_da_rede_municipal_de_uberlandia.pdf $>$. Acesso em: 05 mai .2020.

BENITE, A. M. C.; PEREIRA, L. L. S.; BENITE, C. R. M.; PROCÓPIO, M. V. R. Formação de professores de ciências em rede social: uma perspectiva dialógica na Educação Inclusiva. Revista Brasileira de Pesquisa em Educação em Ciências, v.9, n.3, 2009.

BEZERRA, G. F. Enquanto não brotam as flores vivas: crítica à pedagogia da inclusão. 2012. 270f. Dissertação (Mestrado em Educação) - Universidade Estadual de Mato Grosso do Sul, Paranaíba, 2012. 
A inclusão escolar de alunos com deficiência: uma leitura baseada em Pierre

Bourdieu. Revista Brasileira de Educação v. 22 n. 69 abr.-jun. 2017.

BRASIL. Ministério da Educação e Cultura. Lei no. 9.394, de 20 de dezembro de 1996. Fixa as Diretrizes e Bases da Educação Nacional. Brasília, DF: MEC, 1996.

. Decreto $\mathrm{n}^{\mathrm{o}} 5.626$, de 22 de dezembro de 2005. Regulamenta a Lei $\mathrm{n}^{\circ} 10.436$, de 24 de abril de 2002, que dispõe sobre a Língua Brasileira de Sinais - Libras, e o art. 18 da Lei ${ }^{\circ} 10.098$, de 19 de dezembro de 2000. Diário Oficial da União, Brasília, 23 dez. 2005. Disponível em: < http://www.planalto.gov.br/ccivil_03/_ato20042006/2005/decreto/d5626.htm>. Acesso em: 15 jun de 2020.

Política Nacional de Educação Especial na perspectiva da Educação Inclusiva. Brasília: MEC/SEESP, 2008.

Decreto $\mathrm{n}^{\mathbf{0}}$ 7.219, de 24 de junho de 2010. Dispõe sobre o Programa Institucional de Bolsa de Iniciação à Docência - PIBID e dá outras providências. Disponível em: < http://www.planalto.gov.br/ccivil_03/_Ato20072010/2010/Decreto/D7219.htm>. Acesso em: 15 jan. 2018.

CAPES. PROGRAMA INSTITUCIONAL DE BOLSA DE INICIAÇÃO À DOCÊNCIA - PIBID EDITAL N 2/2020. CAPES: Coordenação de Aperfeiçoamento de Pessoal de Nível Superior, 2020.

COELHO, T. P. C.; BARROCO, S. M. S.; SIERRA, M. A. B. O conceito de compensação em L. S. Vigotski e suas implicações para educação de pessoas cegas. In: $X$ CONPE CONGRESSO NACIONAL DE PSICOLOGIA ESCOLAR E EDUCACIONAL, 2011 E X CONPE CONGRESSO NACIONAL DE PSICOLOGIA ESCOLAR E EDUCACIONAL, 2011. Anais..., 2011.

COSTA. M. C. S. Sentimentos de professores frente às dificuldades na prática da educação inclusiva de alunos com deficiência no ensino fundamental. 2007. Dissertação (Mestrado em Psicologia da Educação) - Pontifícia Universidade Católica, São Paulo, 2007.

CRISTOFOLETI, R. C.; NUNES, I. M. A prática pedagógica e a deficiência intelectual: produção de recursos didáticos. In: PEROVANO, L. P.; MELO, D. C. F. Práticas inclusivas: Saberes, estratégias e recursos didáticos. Campos dos Goytacazes, RJ: Brasil Multicultural, 2019.

DECHICHI, C. Transformando o Ambiente da Sala de Aula em um Contexto Promotor do Desenvolvimento do Aluno Deficiente Mental. 2001. Tese (Doutorado em Psicologia da Educação) - Pontifícia Universidade Católica de São Paulo, São Paulo, 2001.

FERREIRA, J. R. Políticas educacionais e educação especial. Texto apresentado na 23. ${ }^{\mathrm{a}}$ Reunião da ANPEd, 2000.

FREITAS, T. A. A abordagem sócio-histórica como orientadora da pesquisa qualitativa. Cadernos de Pesquisa, n. 116, julho/ 2002.

FREITAS, S. N. A formação de professores na educação inclusiva: construindo a base de todo o processo. In. RODRIGUES, D. (Org.). Inclusão e educação: doze olhares sobre a educação inclusiva. São Paulo: Summus, 2006. p. 161-181.

GIMENEZ, A.; CHAVES, T. O Pibid como espaço de construção de saberes docentes em um curso de Licenciatura em Física. Revista Insignare Scientia - RIS, v. 2, n. 4, p. 219-237, 19 dez. 2019.

GIORDAN, M. Z.; HOBOLD, M. S. Necessidades formativas dos professores iniciantes: temáticas prioritárias para a formação continuada. Formação Docente Revista Brasileira de Pesquisa sobre Formação de Professores, v. 7, n. 12, p. 49-66, 2015.

Recebido em: $30 / 10 / 2019$

Aceito em: $01 / 07 / 2020$ 
GOÉS, M. C. R. Relações entre desenvolvimento humano, deficiência e educação: contribuições da abordagem histórico-cultural. In: OLIVEIRA, M. K.; REGO, T. C.; SOUZA, D. T. Psicologia, educação e temáticas da vida contemporânea. São Paulo: Moderna, 2002.

MANZINI, E. J. Considerações sobre a entrevista para a pesquisa social em educação especial: um estudo sobre análise de dados. In: JESUS, D. M.; BAPTISTA, C. R.; VICTOR, S. L. Pesquisa e educação especial: mapeando produções. Vitória: UFES, 2006

MARCONI. M. A.; LAKATOS, E. M. Fundamentos de metodologia científica. São Paulo: Atlas, 1999.

MARTINS, H. H. T. D. Metodologia qualitativa de pesquisa. Educação e Pesquisa, São Paulo, v.30, n.2, p. 289-300, maio/ago. 2004.

MIZUKAMI, M. G. N. Relações universidade-escola e aprendizagem da docência: algumas lições de parcerias colaborativas. In: BARBOSA, R. L. L. (Org.). Trajetórias e perspectivas de formação de educadores. São Paulo: Editora UNESP, 2004.

MORAES, R. Uma Tempestade de Luz: a compreensão possibilitada pela análise textual discursiva. Ciência \& Educação, São Paulo, v.9, n.2, p. 191-211, 2003.

MORAES, R.; GALIAZZI, M. C. Análise Textual Discursiva. Ijuí/RS: Editora Unijuí, 2007.

KIEREPKA, J. S. N.; ZANON, L. B. Problematização e reconhecimento de teorias e práticas de professores em formação para o ensino de Ciências com foco no educar pela pesquisa. Revista Insignare Scientia - RIS, v. 2, n. 1, p. 1-20, 20 maio 2019.

NÓVOA, A. Novas disposições dos professores - A escola como lugar da formação. Correio da Educação, n. 47, 16 de Fevereiro de 2004.

PAUlA, T. E.; GUIMARÃES, O. M.; SILVA, C. S. Necessidades Formativas de Professores de Química para a Inclusão de Alunos com Deficiência Visual. Revista Brasileira de Pesquisa em Educação em Ciências (RBPEC), v. 17, n.3 2017.

REGO, T. C. Vygotsky: uma perspectiva histórico-cultural da educação. 16. ed. Petrópolis: Editora Vozes, 1995.

SOUZA, E. M. de; MESSEDER, J. C. Célula e Inclusão escolar: Proposta Didática para alunos com deficiência visual. Revista Insignare Scientia - RIS, vol. 3, n. 1. Jan./Abr. 2020.

TIERNEY, W. G. Building Communities of Difference. Higher Education in the twenty-first Century. London: Bergin and Garvey, 1993.

UNESCO. Declaração De Salamanca: Sobre Princípios, Políticas e Práticas na Área das Necessidades Educativas Especiais, 1994, Salamanca-Espanha.

VIGOTSKY, L. S; LURIA, A. R. Estudos sobre a história do comportamento: o macaco, o primata e a criança. Porto Alegre: Artmed, 1996.

VIGOTSKI, L. S. Obras escogidas: fundamentos de defectologia. Madrid: Visor, 1997. v. 5 .

A Defectologia e o estudo do desenvolvimento e da educação da criança anoral. Educação e Pesquisa, São Paulo, v. 37, n. 4, p. 861-870, dez. 2011.

Obras Escogidas - V: Fundamentos de Defectologia. Machado Grupo de distribucion, S. L. 2012.

VILELA-RIBEIRO, E. B. Formação de professores de ciências e educação inclusiva em uma instituição de ensino superior em Jataí-GO. 2011. Dissertação (Mestrado em Educação de Ciências e Matemática), Universidade Federal de Goiás/Regional Goiânia, 2011. 
Vol. 3, n. 5. Set./Dez.

ISSN: 2595- 4520

WARTHA, E. J.; GRAMACHO, R.S. Abordagem problematizadora na formação inicial de professores de Química no Sul da Bahia. In: ECHEVERRIA, A.R.; ZANON, L.B. (orgs.). Formação Superior em Química no Brasil: práticas e fundamentos curriculares. Ijuí: Ed. Unijuí, 2010. p.119-144.

ZAGO, Nadir et all. (Org.). Itinerários de Pesquisa - perspectivas qualitativas em Sociologia da Educação. Rio de Janeiro: DP\&A, 2003.

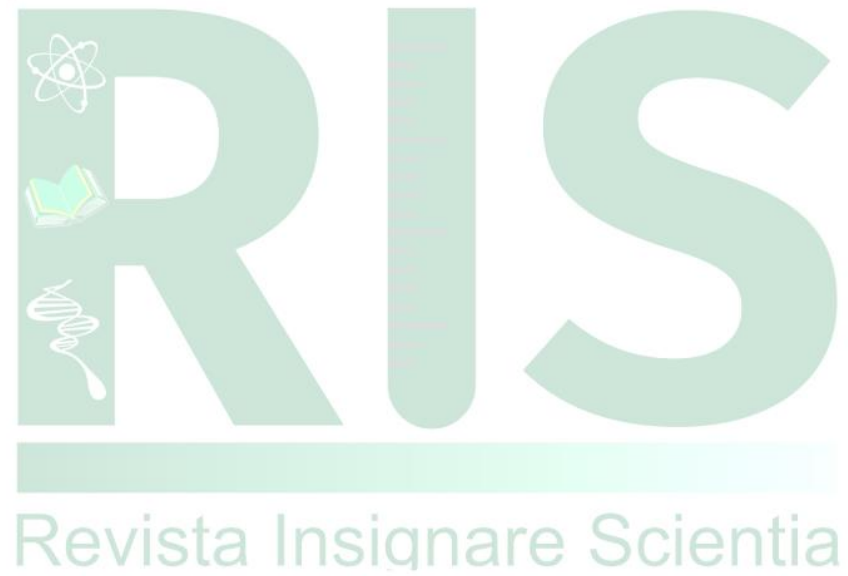

Recebido em: $30 / 10 / 2019$

Aceito em: 01/07/2020 